\title{
A Study on Comparative Analysis of Major Stock Indices of World
}

\author{
Dr. Alpesh Gajera \\ Marwadi Education Foundations' Group of Institutions, Rajkot, India
}

\begin{abstract}
Experts talk lots on integration of major stock indices of the world. In this research paper researcher has tried to establish integration between major stock indices of the world by calculating correlation and applying anova on daily return of 16 major stock indices of the world. In research it is found that preceding and succeeding time of opening the stock market plays vital roles in terms of effect on each other. To achieve the objectives of research, last 5 years daily closing price of these 16 indices is collected and analyzed for quantifying the level of correlation between different stock indices. As sufficient time period is taken and daily closing prices are analyzed so it is found there is not significant difference in the daily return of these stock indices.
\end{abstract}

Key words: STOCK INDEX ; WORLD MAJOR STOCK INDICES ; NIFTY 50 ; SENSEX

\section{Introduction}

A stock market or share market is the aggregation of buyers and sellers of stocks (also called shares), which shows ownership rights on businesses; these may include securities listed on a public stock exchange, as well as stock that is only traded privately, such as shares of private companies which are sold to investors through equity crowd funding platforms. Investment in the stock market is most often done via brokerage houses and electronic trading platforms. Investors make investments as per their investment strategies.

This research focused on the analysis of major stock indices of world. In this research, Researcher have taken previous five years data of sixteen stock indices of world. The analysis includes data of sixteen different stock indices of countries from continents like Asia, Europe, America, Africa, and Australia. Six stock indices are from Asia and five are from Europe. In data collection, Researcher have taken the opening and closing values of all sixteen stock indices of last five years (1st Jan 2015 to 31st Dec 2019). Researcher have calculated returns given by these stock indices on day to day basis and also for the period of five years as a whole.

In this research, Researcher have also stated the opening and closing times of all the selected stock indices as per the Indian standard time. It has played a very important role in getting meaningful findings from the project report. It helped me to find out that which stock indices open earlier than other indices. I can predict the movement of indices at some extent by studying the movement of other indices which opens earlier than them.

\section{II.Literature Review}

Jayshree, 2014: The research gap of this study was found out by conducting a detailed literature review of studies in different countries during the recent years.

Found that the popular belief that the markets in general and Indian market in particular is more integrated with other global exchanges from 2002-03 onwards. This can very well be seen since the South Asian crisis of the mid- late nineties barely affected us particularly because we were insulated due to government policies and was just making the transition. However, in the later time periods, the influence of other stock markets increased on our BSE or NSE, but at a very low almost insignificant level.

Ahmad Raza Bilal, 2013, The purpose was to examine the long-run relationship between gold prices and Karachi Stock Exchange (KSE) and Bombay Stock Exchange (BSE). The statistical techniques used for this study includes Unit Root Augmented Dickey Fuller test, Phillips-Perron, Johnson Cointegration and Granger's Causality tests to measure the long-run relationship between gold prices, KSE and BSE using monthly data from 1st July 2005 to 30th June 2011. Findings of the co-integration test indicated that no long-run relationship exist between monthly average gold prices and KSE stock index; whereas, a significant long-run relationship is proved between BSE stock index and average gold prices. Results of Granger causality test demonstrated that no causal relationship exists among average gold prices, KSE and BSE stock indices. 
Swetadri Samadder, 2018, This study investigated the stock market integration amongst major global stock markets, namely, Australia, Canada, France, Germany, India, UK and USA to examine the short-run and long-run relationships with Indian stock market and selected developed stock markets based on time series data for the period between 2001 (January 2) and 2016 (December 31). This study also examines the possibility of portfolio diversification between the Indian stock market and the developed stock markets. Low correlation is observed between Indian stock market and France stock market that indicates the possible gains from international diversifications. Granger causality test results based on VECM show that both Indian stock market and USA stock market are associated in the long-run but it would take long time to return to equilibrium and Indian stock market is associated with France, Germany and USA stock markets in the short-run, which entails that investors can earn reasonable benefits from international portfolio diversification in the short- run but benefits from international portfolio diversification in the long-run are restricted.

Kaur, 2017, Indian Stock Market has a predominant place in world's economy. Bombay Stock Exchange and National Stock Exchange are having the latest technologies. When compared to stock exchanges of other countries, india holds a very significant place in global stock markets. There are various factors that affect stock exchange including trade barriers or requirements both globally or individually. Bombay stock Exchange is the oldest stock exchange with major index as Sensex and National Stock Exchange has better technologies and has NIFTY 50 as major index.. There are various regulations that are differently applied on different stock exchanges over the world.

Sukhmander Singh, 2018, This paper has been prepared with the intention of capturing the global trends and patterns and the simultaneously flow of the global stock market, as the Indian stock market has been integrated with the world's top stock markets. The stock markets and exchanges covered hereby are of India, USA, China, Taiwan, Japan, Hong Kong, and South Korea and UK during post global financial crisis period. For the purpose of studying the integration of the Indian Stock market with these international Stock exchanges, we include the National Stock Exchange and the Bombay Stock Exchange.

The Time Period taken in this study is from31st Jan 2014 to 31st January 2018 based on daily closing prices of stock market indices for all the selected countries.
Mukherjee, 2007, This study covers New York Stock Exchange (NYSE), Hong Kong Stock exchange (HSE), Tokyo Stock exchange (TSE), Russian Stock exchange (RSE), Korean Stock exchange (KSE) from various sociopolitico-economic backgrounds. Both the Bombay Stock exchange (BSE) and the National Stock Exchange of Indian Limited (NSE) have been used in the study as a part of Indian Stock Market. The time period has been divided into various eras to test the correlation between the various exchanges to prove that the Indian markets have become more integrated with its global counterparts and its reaction are in tandem with that are seen globally.

Menon, 2018, The study at hand compares the Indian Stock Market through BSE and the stock markets in the USA (New York Stock Exchange) and Japan (Tokyo Stock Exchange) to measure and comparatively study where the BSE stands, in comparison with the world's biggest stock markets.

Ishaq Ahmad Bhat, 2014, The present study focuses on analyzing and comparing the efficiency of the capital markets of India and Pakistan. For the purpose of realizing the objectives, Adjusted Daily closing prices of CNX Nifty (NSE India) and KSE 100 (KSE Pakistan) are taken into consideration for the period ranging between 01/04/2003 to 31/03/2013.The researchers have relied on Descriptive Statistics, ADF test, Auto-Correlation test and Jarque-Bera Statistic, Runs test to analyze the data and reach to the results. The results derived by using various parametric and non-parametric tests clearly reject the null hypothesis of the stock markets of India and Pakistan being efficient in weak form. The study provides vital indications to investors, hedgers, arbitragers and speculators as well as the relevance of fundamental and technical analysis as far as the trading/investing in the capital markets of India and Pakistan is concerned.

\section{Research Objective}

$>$ To find out the returns given by the selected stock exchanges.

$>$ Comparing the returns given by selected stock indices to each other.

$>$ Get an idea about the direction of movement of stock indices.

$>$ Find out the correlation between all selected stock indices to measure the strength of movement of stock indices towards each other.

$>$ To find out if the difference between the return of stock indices is significant or not by performing the single factor ANOVA. 
$>$ To get an idea about the dependence of stock indices on the performance of other stock indices.

\section{Research Design}

Here I am using Quantitative Research which is an organized way of gathering and analyzing data obtained from diverse sources. It includes the use of computational, statistical and mathematical tools to derive results.

\section{A. Sampling Design}

Population: Major stock indices are the population for our research

Sample: Researcher have taken 5 years data of stock indices of 16 countries
Sampling Method: Convenience Sampling Method

Sampling Period: 5 Years (i.e.2015 to 2019)

\section{B. Data Collection}

This research report is totally based on the secondary data. Researcher have collected required data from websites and journals which are included in literature reviews

\section{Data Analysis Tools}

$>$ CAGR formula

$>$ ANNOVA: Single Factor

\section{V.Data Analysis and Interpretation}

A. Total returns given by stock indices for the period of 5 years: Period (1st Jan 2015 to 31st Dec 2019)

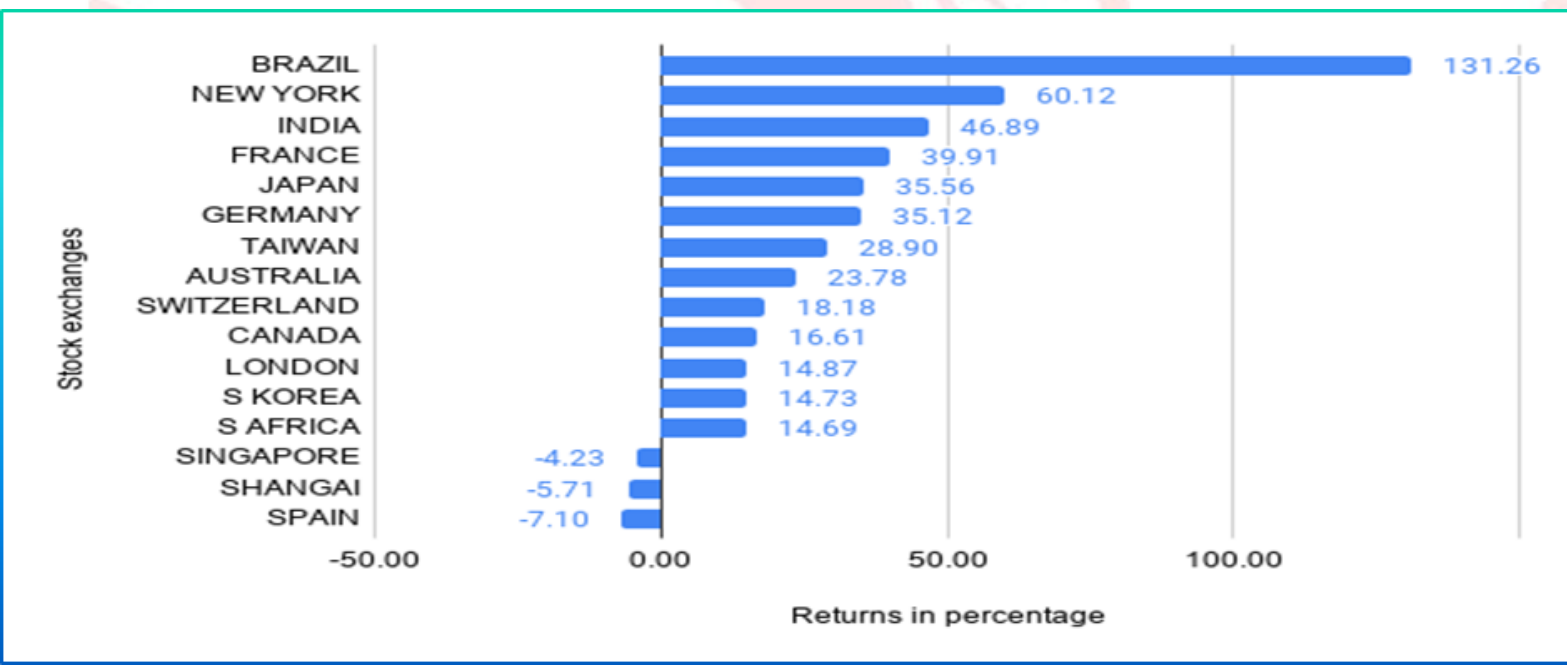

Figure 1: Return of Major stock indices of the world

Interpretation: Stock exchange of Brazil has given the maximum return from the selected stock exchanges. It has given $131.26 \%$ return in last 5 years.

The American stock exchange (New York stock exchange) has given second highest return from the selected stock exchanges.

National stock exchange of India is on the third place by giving $46.89 \%$ return.

Indian stock exchange has given more returns than most of the stock exchanges during the 5 years period. It has given 3rd highest return from the selected stock exchanges. Stock indices with zero or negative returns:
1. Spain $(-7.10 \%)$
2. Shangai $(-5.71 \%)$

\section{Singapore $(-4.23 \%)$}

\section{B. Correlation of stock indices}

Interpretation: From the above correlation analysis of stock indices, we can say that all the stock indices are positively correlated with each other.

That means the stock indices are moving in the same direction. if one indices is going in positive direction then the others will also go towards positive direction. Asian markets have good correlation with each other which is between $20-60 \%$. This means the Asian markets are moving in the same direction with good strength. 
Table 1: Correction of coefficient of return between major stock indices of the world

\begin{tabular}{|c|c|c|c|c|c|c|c|c|c|c|c|c|c|c|c|c|}
\hline & JAPAN & AUSTRAIS & SKOREA & TAIWAN & SINGAPCS & SHANGA & INDIA & GERMANS & SAFRICA & SWITZER & FRANCE & SPAIN & LONDON & BRAZIL & NEW YOI & IADA \\
\hline JAPAN & 1 & & & & & & & & & & & & & & & \\
\hline AUSTRAI & 0.5018 & 1 & & & & & & & & & & & & & & \\
\hline SKOREA & 0.5316 & 0.4141 & 1 & & & & & & & & & & & & & \\
\hline TAIWAN & 0.5020 & 0.4386 & 0.5924 & 1 & & & & & & & & & & & & \\
\hline SINGAPC & 0.4915 & 0.4633 & 0.5255 & 0.5384 & 1 & & & & & & & & & & & \\
\hline SHANGA & 0.2720 & 0.2214 & 0.2851 & 0.3187 & 0.3404 & 1 & & & & & & & & & & \\
\hline INDIA & 0.3392 & 0.2963 & 0.3866 & 0.3954 & 0.4034 & 0.2008 & 1 & & & & & & & & & \\
\hline GERMAN & 0.2863 & 0.2388 & 0.2962 & 0.3064 & 0.3649 & 0.1705 & 0.3736 & 1 & & & & & & & & \\
\hline SAFRICA & 0.2980 & 0.2991 & 0.3787 & 0.4163 & 0.4436 & 0.2245 & 0.3773 & 0.5462 & 1 & & & & & & & \\
\hline SWITZER & 0.2903 & 0.2644 & 0.2803 & 0.3087 & 0.3402 & 0.1243 & 0.3354 & 0.7350 & 0.4767 & 1 & & & & & & \\
\hline FRANCE & 0.3291 & 0.2577 & 0.3263 & 0.3426 & 0.3990 & 0.1794 & 0.3828 & 0.9262 & 0.5702 & 0.7602 & 1 & & & & & \\
\hline SPAIN & 0.3305 & 0.2632 & 0.3054 & 0.3138 & 0.3521 & 0.1453 & 0.3638 & 0.8208 & 0.5109 & 0.6742 & 0.8707 & 1 & & & & \\
\hline LONDON & 0.2949 & 0.3031 & 0.3236 & 0.3683 & 0.3978 & 0.1963 & 0.3751 & 0.7772 & 0.5832 & 0.7089 & 0.8280 & 0.7223 & 1 & & & \\
\hline BRAZIL & 0.1146 & 0.1166 & 0.1603 & 0.1779 & 0.1738 & 0.1109 & 0.1754 & 0.2685 & 0.2908 & 0.2339 & 0.3063 & 0.3112 & 0.3335 & 1 & & \\
\hline NEW YOI & 0.1853 & 0.1494 & 0.2285 & 0.2006 & 0.2278 & 0.1587 & 0.2391 & 0.5156 & 0.3589 & 0.4324 & 0.5377 & 0.4837 & 0.4910 & 0.4034 & 1 & \\
\hline CANADA & 0.2128 & 0.2219 & 0.2446 & 0.2469 & 0.2829 & 0.1654 & 0.2713 & 0.4925 & 0.4081 & 0.4232 & 0.5419 & 0.5007 & 0.5424 & 0.4413 & 0.6708 & 1 \\
\hline
\end{tabular}

European markets have the highest correlation between them which is between 50 to $90 \%$. This means European markets are moving in same direction with high strength. American markets also have a good correlation between them which is $40 \%$ to $67 \%$. That means American markets are also moving in the same direction but with comparatively less strength than European markets.

\section{ANOVA Test}

$\mathbf{H}_{\mathbf{0}}$ - There is no significance difference in the daily return of selected major stock indices of the world.

$\mathbf{H}_{1}$ - There is significance difference in the daily return of selected major stock indices of the world

Table 2: Single factor ANOVA

\begin{tabular}{|c|c|c|c|c|c|c|}
\hline Source of Variation & SS & df & MS & F & P-value & F crit \\
\hline Between Groups & 5.920027 & 15 & 0.394668 & 0.427708 & 0.971869 & 1.666842 \\
\hline Within Groups & 20241.48 & 21936 & 0.922752 & & & \\
\hline Total & 20247.4 & 21951 & & & \\
\hline
\end{tabular}

Interpretation: In single factor ANOVA, if the F value is bigger than the F-crit value than the null hypothesis (there is no significant difference in the daily return of selected major stock indices of the world) is rejected. And if not, the null hypothesis is accepted.

$\mathrm{F}<\mathrm{F}$ crit

In our analysis, the $\mathrm{F}$ value is lower than the F-crit value which means the null hypothesis (there is no significant difference in the daily return of selected major stock indices of the world) is accepted.
From analysis of variance we found out that there is no significant difference in the daily return of the selected major stock indices of the world.

So, the null hypothesis is accepted and the alternate hypothesis is rejected.

\section{Analysis on yearly basis}

Two-way ANOVA

Two-way ANOVA will be performed in which two factors will be studied. 
p-ISSN 2202-2821 e-ISSN 1839-6518 (Australian ISSN Agency)

1. Average return given by individual stock indices in five years.

2. Yearly return from all stock indices for five years on year to year basis.

\section{E. Hypothesis for Stock Indices (Columns)}

Below table shows the average return given by the selected major stock indices every year.

Table - 3: Summary of Anova Test country wise

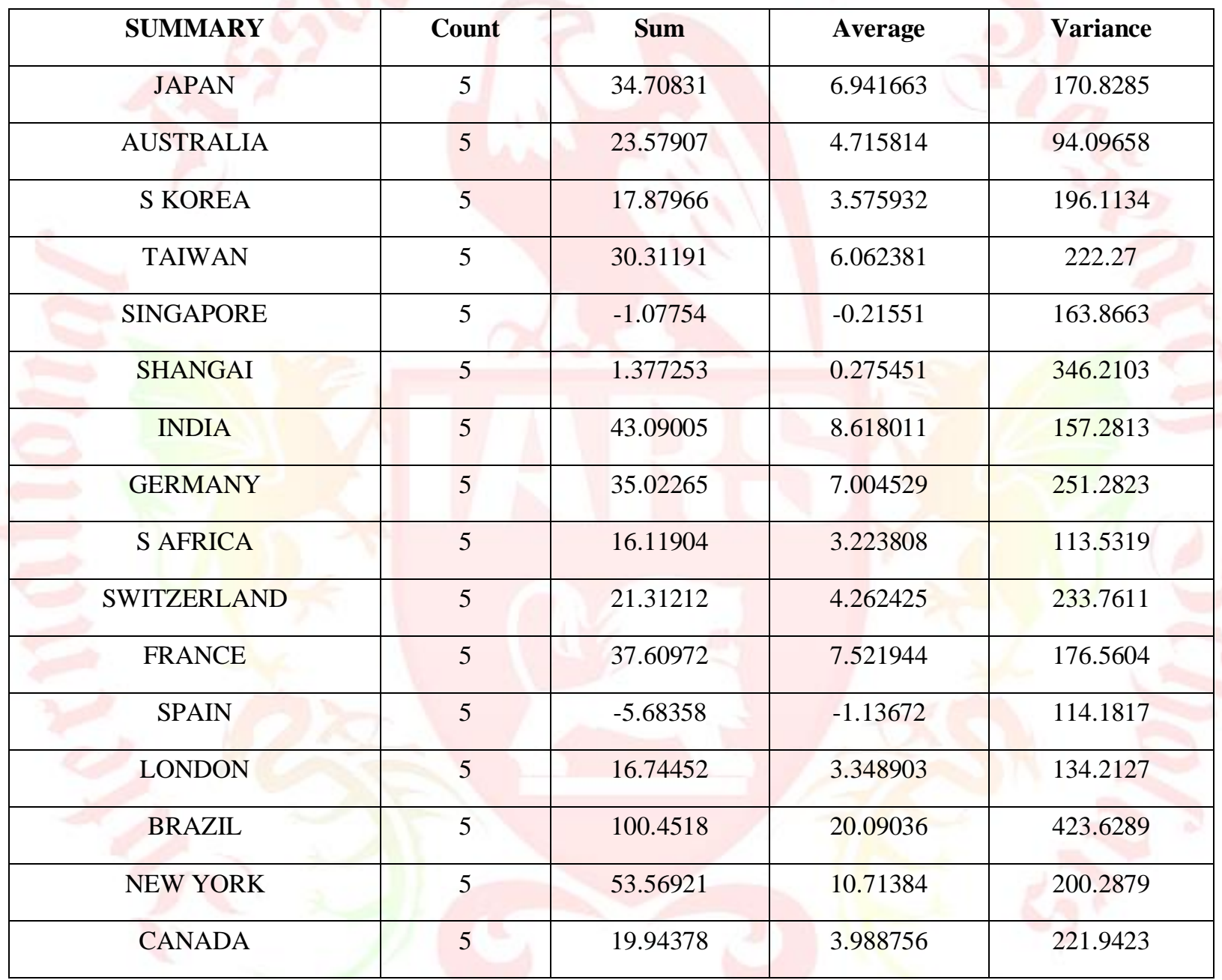

\section{F. Hypothesis for Year (Rows)}

$\mathbf{H}_{\mathbf{0}}$ - There is no significant difference in the return of selected major stock indices of the world on year to year basis.
$\mathbf{H}_{\mathbf{0}}$ - There is no significant difference in the yearly return of selected major stock indices of the world

$H_{1}$ - There is significant difference in the yearly return of selected major stock indices of the world 


\begin{tabular}{|l|l|l|l|l|}
2016 & 16 & 98.9994 & 6.187463 & 137.1175 \\
\hline 2017 & 16 & 242.3571 & 15.14732 & 63.16109 \\
\hline 2018 & 16 & -155.618 & -9.72614 & 81.97126 \\
\hline 2019 & 16 & 289.4571 & 18.09107 & 61.72518 \\
\hline
\end{tabular}

Table - 5: Two way Anova Test Result

\begin{tabular}{|c|c|c|c|c|c|c|}
\hline Source of Variation & SS & df & MS & F & P-value & F crit \\
\hline Rows & 8616.068 & 4 & 2154.017 & 30.30871 & $8.34 \mathrm{E}-14$ & 2.525215 \\
\hline Columns & 1902.098 & 15 & 126.8065 & 1.784267 & 0.05855 & 1.836437 \\
\hline Error & 4264.154 & 60 & 71.06924 & & & \\
\hline Total & 14782.32 & 79 & & & & \\
\hline
\end{tabular}

\section{$>$ Columns (total return from all stock indices on year to year basis)}

$\mathrm{F}$ value is smaller than $\mathrm{F}$ crit

$$
\text { F }<\text { Fcrit }
$$

This means, the null hypothesis H0 (There is no significant difference in the yearly return of selected major stock indices of the world) is accepted.

Returns given by individual stock indices on year to year basis have no significant difference from year to year.

According to this two-way anova, there is significant difference in yearly returns from selected $\mathrm{d}$ stock indices and there is no significant difference in total return from all stock indices on year to year basis.

\section{Rows (yearly return from individual stock indices)}

Here the $\mathrm{F}$ value is bigger than $\mathrm{F}$ crit,

$$
\text { F > Fcrit }
$$

So, the null hypothesis H0 (There is no significant difference in the return of selected major stock indices of the world on year to year basis) will be rejected.

This means that there is significant difference in the total yearly returns from all stock indices.

\section{FINDINGS}

Brazil, New York and Indian stock exchanges have given highest returns respectively in period of five years.
> Spain, Shanghai and Singapore have given lowest returns respectively in period of five years. All of them have given negative return.

$>$ Asian markets open earlier than other stock markets of world.

$>$ Indian stock index has given more return from other five stock indices of Asia in last five years.

$>$ All of the selected major stock indices for our study are positively correlated which means they are moving in the same direction.

$>$ European stock markets are highly correlated because the correlation between them is up to 90 percent.

> Asian and American stock indices are moderately correlated up to 60 and $67 \%$ respectively.

$>$ According to single factor analysis of variance there is no significant difference between the returns of selected major stock indices of the world.

$>$ Highest correlation in our study is between stock indices of Germany and France which is 92 percent on the basis of analysis of daily return.

$>$ Lowest correlation in our study is between stock indices of Brazil and shangai which is 11.09 percent.

$>$ There is no significance difference in the yearly return of selected major stock indices of the world.

$>$ There is significance difference in the return of selected major stock indices of the world on year to year basis. 


\section{CONCLUSION}

A stock market participant at some extent can predict the movement of stock indices opening later than other early opening stock indices based on the performance of those early opening stock indices. There are high probabilities of having a high correlation between stock indices belonging to same continent. European stock indices are the most correlated indices from selected major stock indices of the world. All sixteen stock indices from our study are positively correlated which means they all are moving in the same direction. Lower correlation is seen between the stock indices belonging to different continents as compared to those belonging to same continent.

Positive correlation is seen between all stock indices which means all are moving in the same direction. Strength of movement depends upon the level of correlation. A good performance by the major stock indices of a country represents the good economic health and progress of that country. For example, stock markets of most of the countries are facing decrease in value because of corona virus pandemic.

\section{REFERENCES}

1. AHMAD RAZA BILAL, N. B. (2013). How gold prices correspond to stock index: a comparative analysis of Karachi stock exchange and Bombay stock exchange. World applied sciences journal, 7.

2. ISHAQ AHMAD BHAT, S. Q. (2014). A comparative analysis of the efficiency of the stock markets of India and Pakistan. Global journal of finance and management, 8.

3. JAYSHREE, S. (2014). A comparative study of BSE and international stock exchanges with special reference to pharmaceutical industries. IOSR journal of business and management (IOSR-JBM), 19.

4. KAUR, R. (2017). Comparative analysis of Indian stock exchange and major index with global stock exchange and their major index. International journal of management and applied science, 8.

5. MENON, S. (2018). A comparative study of the Indian stock market with two international stock markets between 2012-17. International journal of engineering technology science and research, 14.

6. MUKHERJEE, D. (2007). Comparative analysis of Indian stock market with international markets. Great lakes herald, 33.

7. SUKHMANDER SINGH, D. K. (2018). Comparative analysis of Indian stock market with international markets. International journal of advanced research in science and engineering, 11.

8. SWETADRI SAMADDER, A. B. (2018). Integration between Indian stock market and developed stock markets. 11 . 